\title{
Under which conditions can introverts achieve happiness? Mediation and moderation effects of the quality of social relationships and emotion regulation ability on happiness
}

Rosario Cabello, Pablo Fernandez-Berrocal

Personality traits have been directly associated with happiness. One consistent finding is a strong link between extraversion and happiness: extraverts are happier than introverts. Although happy introverts exist, it is currently unclear under what conditions they can achieve happiness. The present study analyzes, generally, how the quality of social relationships and emotion regulation ability influence happiness and, specifically, how these factors can lead introverts to be happy. In the present study, 1006 participants aged 18 to 80 (42\% males) completed measures of extraversion, neuroticism, quality of social relationships, emotion regulation ability, and happiness. We found that extraverts had significantly higher happiness, quality of social relationships and emotion regulation ability scores than introverts. In addition, people with a high quality of social relationships or high emotion regulation ability were happier. Serial mediation analyses indicated that greater levels of extraversion were associated with greater happiness, with small effect size, via two indirect mechanisms: (a) higher quality of social relationships, and (b) higher quality of social relationships followed serially by higher emotion regulation ability. We also found a moderating effect due to the three-way interaction of extraversion, quality of social relationships, and emotion regulation ability: introverts were happier when they had high scores for these two variables, though the effect size was small. These results suggest that the quality of social relationships and emotion regulation ability are relevant to our understanding of complex associations between extraversion and happiness. 


\section{Under which conditions can introverts achieve happiness? Mediation and moderation effects of the quality of social relationships and emotion regulation ability on happiness}

\section{Rosario Cabello , and Pablo Fernández-Berrocal ${ }^{2 *}$}

${ }^{1}$ Department of Psychology, Faculty of Education Science, University Castilla-La Mancha, Ciudad Real, Spain.

${ }^{2}$ Department of Basic Psychology, Faculty of Psychology, University of Málaga, Spain.

* Correspondence: Pablo Fernández-Berrocal, Department of Basic Psychology, Faculty of Psychology, University of Malaga, Campus Teatinos s/n, 29071, Spain.

berrocal@uma.es

Keywords: happiness, extraversion, emotion regulation ability, quality of social relationships, mediate, moderate

\section{Abstract}

Personality traits have been directly associated with happiness. One consistent finding is a strong link between extraversion and happiness: extraverts are happier than introverts. Although happy introverts exist, it is currently unclear under what conditions they can achieve happiness. The present study analyzes, generally, how the quality of social relationships and emotion regulation ability influence happiness and, specifically, how these factors can lead introverts to be happy. In the present study, 1006 participants aged 18 to 80 (42\% males) completed measures of extraversion, neuroticism, quality of social relationships, emotion regulation ability, and happiness. We found that extraverts had significantly higher happiness, quality of social relationships and emotion regulation ability scores than introverts. In addition, people with a high quality of social relationships or high emotion regulation ability were happier. Serial mediation analyses indicated that greater levels of extraversion were associated with greater happiness, with small effect size, via two indirect mechanisms: (a) higher quality of social relationships, and (b) higher quality of social relationships followed serially by higher emotion regulation ability. We also found a moderating effect due to the three-way interaction of extraversion, quality of social relationships, and emotion regulation ability: introverts were happier when they had high scores for these two variables, though the effect size was small. These results suggest that the quality of social relationships and emotion regulation ability are relevant to our understanding of complex associations between extraversion and happiness. 


\section{Introduction}

Personality is one of the personal factors that most influences happiness, as Aristotle (trans. 1984) first pointed out 2,300 years ago and as scientific studies of the 21 st century confirm (Diener and Seligman, 2002). Research has indicated a strong influence of extraversion on happiness, showing that extraverts are happier than introverts (DeNeve and Cooper, 1998; Hills and Argyle, 2001; Lucas, 2007; Steel et al., 2008). Although happy introverts exist, it is currently unclear under what conditions they can achieve happiness (Argyle and Lu, 1990). The present study takes a closer look at this question by analyzing how quality of social relationships and emotion regulation ability may positively affect the happiness of introverts, especially in large community-based samples.

Happiness is described as a life involving many pleasant and few unpleasant experiences, and as the experience of high life satisfaction (Schimmack et al., 2004). In general, we apply in the present work a broad conceptualization of happiness including both affective and cognitive components based on Lyubomirsky's approach (Lyubomirsky et al., 2005; Lyubomirsky and Lepper, 1999) . This perspective attempts to identify people who are global and chronically happy (or unhappy) by directly asking them about their general subjective happiness. This judgment is not merely the simple summation of recent levels of positive and negative affect and satisfaction with life. Although studies have found positive correlations of subjective happiness with life satisfaction and with positive and negative affect, with coefficients ranging from 0.52 to 0.72 (e.g., Lyubomirsky and Lepper, 1999), the correlations are not large enough to justify completely overlaying these concepts.

Although positive affect may seem essential for happiness, and it is often used interchangeably with happiness in the research literature, positive affect does not adequately capture the concept of happiness, it does not guarantee happiness, and it may be unrelated to many of our happiest experiences (Diener and Seligman, 2002; Lyubomirsky et al., 2005). Nevertheless, several studies have assessed positive affect as an indicator of happiness, and we occasionally draw on those studies in the present work in the absence of studies directly measuring happiness.

We begin our review of the literature by briefly discussing the association between extraversion and happiness, and then discuss how this link may be affected by the quality of social relationships and the ability to regulate emotions adaptively and positively in social interactions.

\section{Extraversion and happiness}

Of the five dimensions of personality, extraversion and neuroticism have shown the greatest influence on happiness, with extraversion linked positively and neuroticism negatively to happiness. More specifically, extraversion positively correlates with various happiness measures with correlation coefficients of 0.17-0.45 (Argyle et al., 1995; DeNeve and Cooper, 1998; Cheng and Furnham, 2003). Recently, Cheng and Furnham (2014) showed using a longitudinal design and community sample that extraversion is a significant predictor of happiness, after controlling for parental factors, the subject's own social factors and intelligence during childhood. Thus extraversion is one of the personality factors most tightly associated with the various cognitive and affective indicators of happiness (Hills and Argyle, 2001; Lucas, 2007; Lucas and Fujita, 2000; Steel et al., 2008). In other words, it is easier for extraverts than introverts to be happy. 
Nevertheless, happy introverts do exist: Hills and Argyle (2001) found that among 133 participants who reported being happy, 33\% were introverts.

Explanations for why extraversion leads to higher happiness indices are controversial, and they range from arguments based on brain structure to arguments grounded in instrumental associations with social relationships (Cremers et al., 2011; Lischetzke and Eid, 2006; Oerlemans and Bakker, 2014; Smillie et al., 2012). Despite the clear association between extraversion and happiness, variables that may mediate and moderate it have yet to be examined systematically and simultaneously, especially in large community-based samples. Two such variables are quality of social relationships and emotion regulation ability.

\section{Quality of social relationships}

Studies using instrumental models have shown that social relationships partly explain the relationship between extraversion and happiness (Hills and Argyle, 2001; Argyle and Lu, 1990). Lee et al. (2008) found social connectedness (a person's subjective awareness of being in close relationship with the social world) mediated the association between extraversion and subjective well-being. This is consistent with studies showing that happy people have significantly more full and satisfying interpersonal lives than do people of average happiness or people who are very unhappy (Diener and Seligman, 2002).

Other studies, however, do not support this conclusion and instead report that happiness shows only small correlations with number of friends, frequency of contact, marital status, and actual social activity; effect sizes for these correlations range from 0.10 to 0.20 , smaller than those for other variables often interpreted as irrelevant, such as income and health (see Lucas et al. 2008 for a review). Consistent with the idea that temperament directly mediates the association between extraversion and positive affect, Lucas et al. (2008b) showed in two studies that even after controlling for differences in levels of social activity and in reactivity to social activity, extraverts still reported greater positive affect than did introverts.

One reason why the existence of social relationships and the amount of time people spend with social relationship partners may not guarantee a high level of happiness is that the social relationships are of insufficient quality. Researchers have proposed that the quality of social relationships can influence the effect of social relationships on happiness (Lyubomirsky et al., 2005). Hotard et al. (1989) found that strength of social relationships was a strong moderator of subjective well-being in introverted individuals, but not in extraverted ones. More recently, Lucas et al. (2008b; study 2) analyzed extraversion as a moderator of the association between social activity and positive affect and showed a direct association between extraversion and positive affect. These studies highlight the need to analyze the quality of social relationships as both possible mediator and moderator of the relationship between extraversion and happiness.

\section{Emotion regulation ability}

Emotion regulation ability involves being aware of the most effective strategies to modify and nurture emotions in particular situations. It is part of the emotion regulation branch within the Mayer and Salovey ability model of emotional intelligence (Mayer and Salovey, 1997). Several reviews describe considerable evidence for the validity of this type of emotional intelligence in different personal and professional contexts (Coté, 2014; Joseph and Newman, 2010). Emotion 
117 regulation ability is linked with happiness: people who intelligently regulate their emotions 118 obtain high scores on several measures of happiness (Côté, 2014).

119 It is unclear whether personality factors moderate the association between the ability model of 120 emotional intelligence and happiness. Several studies failed to find any association between ability emotional intelligence scales and happiness indicators after controlling for personality dimensions (Bastian et al., 2005; Zeidner and Olnick-Shemesh, 2010). On the other hand, crosssectional studies (Brackett and Mayer, 2003; Brackett et al., 2006) and prospective studies (Extremera et al., 2011) found that ability emotional intelligence explained 1-4\% of variance in happiness measures after controlling for Big Five personality dimensions.

The hypothesis that emotional regulation mediates the effect of extraversion on happiness has been examined in some studies using self-reported measures of emotional intelligence or emotional regulation. Lischetzke and Eid (2006) found that mood maintenance, but not mood repair, mediated the effect of extraversion on pleasant-unpleasant trait mood and pleasantunpleasant affect change. Other studies suggest possible cultural and genetic bases for emotional regulation as a mediator: self-reported emotional intelligence mediated the effects of extraversion on happiness in a community sample in the UK (Chamorro-Premuzic et al., 2007), but not in such a sample in India (Hafen et al., 2011).

Several studies indirectly suggest that emotion regulation ability may be a mediator or moderator of the relationship between extraversion and happiness. Emotion regulation ability has been linked to the quality of social relationships (Brackett et al., 2006; Lopes et al., 2003, 2011; Mayer et al., 2008a for a review). One study found that, after controlling for personality differences among people with low levels of self-reported emotional intelligence, the level of perceived social support interacted with emotional intelligence to produce higher positive affect (Gallagher and Vellabrodrick, 2008). In contrast, perceived social support and emotional intelligence did not interact to influence subjective well-being. One study showed that adolescents who scored high on extraversion and had greater self-reported emotional intelligence also scored higher on happiness (Salami, 2011). These mediation and moderation hypotheses need to be explored using a measure of emotion regulation ability.

\section{Motivation for the present study}

The above literature review provides evidence of direct relationships between happiness on one hand, and extraversion, social relationships and emotion regulation on the other. In fact, studies have suggested that social relationships or emotion regulation ability help mediate or moderate the relationship between extraversion and happiness. However, the evidence is inconclusive: the strength of moderation varies substantially with experimental conditions, and some studies have shown that controlling for personality dimensions eliminates observed correlations of social relationships and emotion regulation ability with happiness. We are unaware of studies analyzing these two variables acting separately and in concert as potential mediators and moderators of the relationship between extraversion and happiness in a large community sample.

Therefore the present study aimed to develop and test different models that consider quality of social relationships and emotion regulation ability as mediator and/or moderator variables that explain or enhance the effects of extraversion on happiness in an adult community sample (Figures 1 and 2). Emotion regulation ability was evaluated using the Mayer-Salovey-Caruso 
159 Emotional Intelligence Test (MSCEIT). This work aims to help fill in several gaps in the 160 research literature. One is the need to address the research question while avoiding the high risk 161 of bias associated with self-reported measures of emotional intelligence or emotion regulation 162 used in most studies on this topic. Self-reported measures do not directly assess people's 163 emotional abilities but rather people's self-reported beliefs about their emotional abilities. Self164 reported emotional intelligence measures are highly correlated with established measures of 165 happiness and personality and may therefore contain a great deal of unwanted variance (Côté, 166 2014; Brackett et al., 2006; Webb et al., 2013). Another gap addressed in the present study is 167 whether and how the quality of social relationships affects happiness; most relevant studies have 168 focused instead on the number or amount of social relationships. A third gap is to examine 169 mediation or moderation in a large community sample with people of diverse ages, since most 170 relevant studies have been performed with small undergraduate samples.

171 Several hypotheses guided the design and interpretation of the present study. First, we expected 172 that, as indicated by the literature, extravert personality, quality of social relationships and 173 emotion regulation ability would be associated with happiness. Second, we expected that quality 174 of social relationships and emotion regulation ability would be related with happiness even after controlling for the influence of extraversion and neuroticism. We included the personality trait neuroticism as a control variable because emotionally stable individuals generally experience greater happiness (DeNeve and Cooper, 1998). Third, we expected that the quality of social relationships and emotion regulation ability would simultaneously mediate the relationship between extraversion and happiness. Finally, and most importantly for the present study, we expected that quality of social relationships and emotion regulation ability would moderate the relationship between extraversion and happiness such that, in line with previous research, introverts with a higher quality of social relationships and higher emotion regulation ability would score higher on happiness scales.

2. Materials and methods

\subsubsection{Participants}

The sample consisted of 1006 White/Caucasian Spanish volunteers (42\% males) aged 18 to 80 (mean age $=39.53, \mathrm{SD}=14.96$, median age $=45$, interquartile range $=22-52$ ).

\subsubsection{Instruments}

Emotion regulation ability. We assessed emotion regulation ability using the MSCEIT 2.0 (Mayer et al., 2002; Spanish version by Extremera et al., 2006). MSCEIT uses 141 items to assess the four primary abilities (branches) of the Mayer and Salovey model of emotional intelligence: perceiving emotions in oneself and others, using emotions to facilitate thought, understanding emotional information, and regulating emotions in oneself and others (Mayer and Salovey, 1997). In the present study, we used only the emotion regulation branch of the MSCEIT, which assesses intra- and interpersonal emotion regulation abilities in separate tasks totaling 29 items. Respondents rate the effectiveness of different strategies for regulating their own feelings in specified situations and for managing emotionally challenging interpersonal situations. Specifically, the items ask respondents to evaluate the effectiveness of various strategies to generate, maintain, or suppress emotions in the situations described. Raw scores on each task were obtained using a consensus scoring criterion, then transformed into standard 
scores with a mean of 100 and a standard deviation of 15 . Confirmatory factor analysis of responses from 2,112 adults has shown that emotion regulation ability is one of four emotional abilities measured by the MSCEIT (Mayer et al., 2003). The split-half reliability of this subscale was measured to be 0.81 (Mayer et al., 2003), with a test-retest correlation of 0.86 (Brackett and Mayer, 2003).

Happiness. Participants were administered the Subjective Happiness Scale (SHS; Lyubomirsky and Lepper, 1999; Spanish version by Extremera and Fernández-Berrocal, 2014), a widely used 4-item global assessment of happiness. Two items ask respondents to describe themselves using both absolute ratings and ratings relative to peers, while the other two items offer brief descriptions of happy and unhappy individuals and ask respondents about the extent to which each description describes them. Each item is assessed on a Likert scale ranging from 1 (Not a very happy person) to 7 (A very happy person); for example, Item 1 is "In general I consider myself...". The SHS has demonstrated good psychometric properties such as test-retest reliability, discriminant validity and convergent validity across 14 samples (Lyubomirsky and Lepper, 1999) and in samples from different cultures (Extremera and Fernández-Berrocal, 2014).

Extraversion and Neuroticism. These personality traits or factors were assessed using the extraversion and neuroticism scales of the Big Five Inventory-44 (BFI-44; John and Srivastava, 1999; Spanish version by Benet-Martínez and John, 1998). The BFI-44 is a 44-item, self-report inventory designed to assess the Big Five factors of personality: Extraversion, Agreeableness, Conscientiousness, Neuroticism and Openness to Experience. In the present study we used the eight items of the extraversion scale and the eight items of the neuroticism scale. These scales, like the others on the BFI-44, have shown substantial internal consistency (extraversion $\alpha=0.88$, neuroticism $\alpha=0.84$ ), test-retest reliability and clear factor structure.

Quality of Social Relationships. The Network of Relationships Inventory (NRI; Furman, 1996; Furman and Buhrmester, 1985; Spanish version by Lopes et al., 2011) consists of 30 items assessing different dimensions of social relationships. In our study, we assessed the quality of social relationships using an abridged, 12-item version of the NRI with only one dimension that focuses on companionship, intimacy, affection, and alliance. The dimension includes items such as "how often do you tell this person everything that you are going through?" Participants used a 9-point Likert scale to evaluate to what extent each of the statements occurs in their relations with friends, i.e. with people who are neither family nor romantic partners. The psychometric properties of this scale have been well demonstrated, with a reported Cronbach's alpha of 0.88 (Furman, 1996; Lopes et al., 2011).

\subsubsection{Procedures}

Participants were recruited via posters on the local university campus, at retirement homes and in local newspapers. Participants were accepted into the study to ensure a broad, balanced distribution of gender, age, and socio-economic status. Data were collected over two consecutive years with the help of a team of research assistants. Participants completed paper questionnaires individually in small groups under the supervision of research assistants at different educational centers. They received no financial compensation for participation in the study.

The study was carried out in accordance with the Declaration of Helsinki and ethical guidelines of the American Psychological Association. The study protocol was approved as part of the 
projects SEJ-07325 and PSI2012-37490 by the Research Ethics Committee of the University of 244 Málaga.

\section{5}

\subsubsection{Statistical analysis}

Preliminary analyses were carried out to compute descriptive statistics and internal consistency, as well as to detect correlations among extraversion, quality of social relationships, emotion regulation ability and happiness. These analyses were carried out using the SPSS package (version 20.0; IBM, Chicago, IL).

To check whether quality of social relationships and emotion regulation ability are related to happiness even after controlling for the influence of extraversion and neuroticism, we conducted four-step hierarchical regression in which gender and age were entered first (as control variables), followed by extraversion and neuroticism, then quality of social relationships, and finally emotion regulation ability. To examine whether quality of social relationships and emotion regulation ability mediate the relationship between extraversion and happiness, we performed serial mediation analysis using Model 6 in the PROCESS tool (Hayes, 2013). PROCESS is an SPSS macro for mediation, moderation and conditional process modeling. It allows for one independent variable, one dependent variable, and more than one simultaneous mediator variable. To directly test our proposed moderation model (Figure 2), we used Model 3 in PROCESS to develop and analyze a three-way interaction model (Hayes and Matthes, 2009; Preacher et al., 2007). The PROCESS macro automatically determines the centering and interaction terms and provides the point estimate and first- and second-order variance estimates of the conditional indirect effect for a given set of moderator values. We used the JohnsonNeyman computational technique (Hayes, 2013) to identify the values of the moderating variable for which the independent and dependent variables showed a significant association.

\section{Results}

\subsection{Sample characteristics and correlations between key variables}

Table 1 shows descriptive statistics for the total sample and for men and women separately, as well as the range of variable values, Cronbach's $\alpha$ and correlation of main variables with age. Age showed significant negative correlations with neuroticism, quality of social relationships and emotion regulation ability, but no correlation with happiness or extraversion. We repeated the analysis treating age as a categorical variable and obtained similar results.

Table 2 shows correlations among the main variables in our study. As expected, we found positive correlations between happiness on one hand, and extraversion, quality of social relationships, and emotion regulation ability on the other. Extraverts received higher happiness scores than introverts. Neuroticism negatively correlated with happiness.

Four-step hierarchical regression to check whether quality of social relationships and emotion regulation ability are related to happiness even after controlling for the influence of extraversion and neuroticism generated a significant overall model $[F(6,999)=71.88, p<.001$, with an adjusted $\left.R^{2}=.30\right]$. Neither gender nor age was associated with happiness. The personality traits of extraversion $(\beta=0.23, p<.001)$ and neuroticism $(\beta=-0.35, p<.001)$ were, respectively, positively and negatively associated with happiness $\left(\Delta R^{2}=.24\right)$. In addition, both quality of 
social relationships $\left(\beta=0.20, p<.001 ; \Delta R^{2}=.04\right)$ and emotion regulation ability $(\beta=0.13, p<$ $\left..001 ; \Delta R^{2}=.02\right)$ were positively associated with happiness.

\subsection{Mediation analyses}

We created a serial multiple mediation model (Hayes, 2013) using quality of social relationships and emotion regulation ability as mediators. Gender, age, and neuroticism were controlled throughout these analyses. In serial mediation, mediators are assumed to have a direct effect on each other (Hayes, 2013), and the independent variable (extraversion) is assumed to influence mediators in a serial way that ultimately influences the dependent variable (happiness). As illustrated in Figure 1, a total effect $(c)$ refers to the relationship between extraversion and happiness without controlling for mediators; a direct effect $\left(c^{\prime}\right)$, to the relationship between extraversion and happiness after controlling for mediators; a total indirect effect $(a b)$, to the role of two mediators in the relationship between extraversion and happiness; and a specific indirect effect $\left(a_{1} b_{1}\right.$ and/or $\left.a_{2} b_{2}\right)$, to the role of a particular mediator in the relationship between extraversion and happiness. From our serial multiple mediation model involving quality of social relationships and emotion regulation ability as mediators, we obtained three specific indirect effects through (1) the quality of social relationships $\left(a_{1} b_{1}\right),(2)$ the quality of social relationships and emotion regulation ability $\left(a_{1} a_{3} b_{2}\right)$, and (3) emotion regulation ability $\left(a_{2} b_{2}\right)$ (Figure 1$)$.

The results showed significant total $(c)$ or direct effects $\left(c^{\prime}\right)$ of extraversion on happiness (Table $3)$. The total indirect effects of extraversion $(a b)$ were statistically significant, since the $95 \%$ confidence interval (CI) of the point estimate did not cross zero. Two significant specific indirect effects were also found. First, there was a significant indirect pathway for extraversion through quality of social relationships $\left(a_{1} b_{1}\right)$. Greater extraversion was associated with higher quality of social relationships, which was itself associated with greater happiness. Second, there was a significant indirect pathway for extraversion through quality of social relationships and emotion regulation ability $\left(a_{1} a_{3} b_{2}\right)$. Greater extraversion was serially associated with higher quality of social relationships and emotion regulation ability, both of which were associated with greater happiness. No indirect effect of emotion regulation ability was found for the association of extraversion and happiness $\left(a_{2} b_{2}\right)$.

\subsection{Moderation analyses}

We used extraversion, quality of social relationships and emotion regulation ability as indicator variables and happiness as the criterion factor (Figure 2). Gender, age, and neuroticism were included as control variables. We tested all two-way interactions (fifth-step; extraversion $x$ quality of social relationships, extraversion $x$ emotion regulation ability, quality of social relationships $x$ emotion regulation ability) and the three-way interaction (sixth-step; extraversion $x$ quality of social relationships $x$ emotion regulation ability). Moderation analysis on happiness revealed a significant three-way interaction among extraversion, quality of social relationships and emotion regulation ability $\left(\beta=-0.062, p<.01 ; \Delta R^{2}=.01\right)$. Two-way interactions between these variables were not significant.

Figure 3 shows regions of significance for happiness using the Johnson-Neyman technique. Among introverts, defined as those scoring at least $1 S D$ below the mean on the extraversion scale, quality of social relationships significantly increased self-reported happiness in those who 
had above-average levels of emotion regulation ability. This variable began to exert a moderating effect at emotion regulation ability scores above $113.15(t=-1.96, p<.05)$. In particular, introverts with a high quality of social relationships and an emotion regulation ability score above 113.15 obtained a mean happiness score of 5.25, which was higher than the mean score of 4.65 for all introverts, and $1 S D$ above the mean score of 4.28 for introverts with a low quality of social relationships and low emotion regulation ability. As Figure 3A shows, there was a positive effect of quality of social relationships on happiness for introverts with high emotion regulation ability $(b=0.067, t=4.07, p<.001)$. However, there was no effect of quality of social relationships on happiness for introverts with low emotion regulation ability $(b=0.034, t=1.62$, $p>.10)$.

In contrast, among extraverts, defined as those at least $1 S D$ above the mean on the extraversion scale, quality of social relationships significantly increased reported happiness in all individuals except those with very low emotion regulation ability. This variable began to exert a moderating effect at emotion regulation ability scores below $76.15(t=1.96, p<.05)$. More specifically, extraverts with a low quality of social relationships and emotion regulation ability scores below 76.15 obtained a mean happiness score of 4.80 , which was below the mean score of 5.49 for all extraverts, and $1 S D$ below the mean of 5.85 for extraverts with a high quality of social relationships and high emotion regulation ability. As Figure 3B shows, there was a positive effect of quality of social relationships on happiness for extraverts with low emotion regulation ability $(b=0.068, t=4.22, p<.001)$. However, there was no effect of quality of social relationships on happiness for extraverts with high emotion regulation ability $(b=0.025, t=$ $1.57, p>.10)$.

\section{Discussion}

The present findings support the existence of several relations between happiness on one hand and extraversion, quality of social relationships, and emotion regulation ability on the other. The pattern of correlations indicates that individuals with more extraverted and less neurotic personalities report higher happiness. This finding confirms previous research reporting a strong association of happiness with the personality factors extraversion and neuroticism (Cheng and Furnham, 2014; DeNeve and Cooper, 1998; Hills and Argyle, 2001; Lucas, 2007; Steel et al., 2008). Even after controlling for these two personality factors, as well as for gender and age, quality of social relationships and emotion regulation ability still showed a significant association with happiness. Thus, our study suggests that people with a high quality of social relationships or high emotion regulation ability are happier, consistent with previous studies (Diener and Seligman, 2002; Brackett et al., 2006).

The presence and small effect size (2-4\%) of correlations between happiness and quality of social relationships and emotion regulation ability are consistent with research supporting the relevance of social relationships on happiness (Hotard et al., 1989; Lee et al., 2008), as well as with the reported discriminant and predictive validity of emotional intelligence evaluated as an ability (Brackett and Mayer, 2003; Brackett et al., 2006; Extremera et al., 2011; Mayer et al., 2008a; Webb et al., 2013). At the same time, our study provides important new insights. Whereas previous work focused on how social relationships or higher emotion regulation ability on their own affect the association between extraversion and happiness, we examine these factors in conjunction and provide the first evidence that they may simultaneously influence happiness. 
367 Our results suggest that extraversion influences happiness through direct and indirect processes.

368 In our serial mediation model, extraversion had a direct effect on happiness, which is consistent 369 with previous research establishing a concurrent association between the personality trait 370 extraversion and happiness (DeNeve and Cooper, 1998). In addition, we found that greater levels 371 of extraversion were associated with greater happiness (a) indirectly via a higher quality of social 372 relationships, and (b) both indirectly and serially via higher quality of social relationships and 373 higher emotion regulation ability. This is consistent with previous research proposing that social 374 relationships mediate the association between extraversion and happiness (Argyle and Lu, 1990; 375 Lee et al., 2008). Those studies focused more on the amount of social relationships, whereas we 376 focused on the quality of relationships. In this sense, our study complements and extends the 377 literature.

378 Our results with emotion regulation ability are consistent with findings from studies suggesting 379 that emotional regulation or self-reported emotional intelligence mediate the link between 380 extraversion and happiness (Lischetzke and Eid, 2006; Chamorro-Premuzic et al., 2007; Hafen et 381 al., 2011). Those studies relied on self-reported measures of emotional intelligence; we, in 382 contrast, used the MSCEIT and focused on emotional intelligence as an ability measure. In this 383 way, our results significantly extend the literature. Indeed, our analysis is the first to provide 384 evidence that mediation occurs serially via higher quality of social relationships. This may mean 385 that the ability to regulate emotions based on experience strengthens social attachments and 386 avoids friction with friends, contributing to positive and successful social interactions that 387 generate more happiness (English et al., 2012; Lopes et al., 2003, 2011).

388 In addition to providing insights into how quality of social relationships and emotion regulation 389 ability may mediate the association between extraversion and happiness, our study performs the 390 first analysis of three-way interactions among the variables. Our goal was to determine whether 391 quality of social relationships and emotion regulation ability moderate the effects of extraversion 392 on happiness. As expected, we found evidence of weak but significant moderation: introverts 393 were happier when they had high quality of social relationships and high emotion regulation 394 ability. Extraverts were less happy when they had a low quality of social relationships and low 395 emotion regulation ability, but not when they had high emotion regulation ability. These findings 396 suggest that in introverts, high emotion regulation ability reinforces the positive effects of quality 397 of social relationships, thereby increasing happiness. In fact, introverts in our study who had high 398 quality in their social relationships and high emotion regulation ability showed a mean happiness 399 score of 5.25, which is above the mean for the general Spanish population $(M=5.09$; Extremera 400 et al., 2011). In extraverts, low emotion regulation ability weakens the positive effects of quality 401 of social relationships on happiness, suggesting that extraverts with low emotion regulation 402 ability may find it difficult to obtain positive experiences from their social relationships. These 403 findings are consistent with previous research proposing that strength of social relationships 404 moderates the association between extraversion and subjective well-being (Hotard et al., 1989), 405 and with other studies concluding that self-reported emotional intelligence moderates the 406 association between extraversion and happiness (Salami, 2011) or between social relationships 407 and life satisfaction (Gallagher and Vellabrodrick, 2008). Therefore, even small changes to 408 social relations or an individual's abilities can have important effects for the course of his or her 409 life (Brackett and Mayer, 2003; Brackett et al., 2006; Extremera et al., 2011).

\section{Limitations and future directions}


The cross-sectional nature of our study and its reliance on a single instrument to assess different constructs precludes inferences about causality in the relationships among variables studied. While our mediation analyses support the notion that quality of relationships and emotion regulation ability lead to greater happiness, prospective studies are needed to address this question rigorously. Nevertheless, our data clearly suggest that researchers should consider alternative mediation and moderation models when analyzing relationships between personality factors and happiness.

Though brief, the SHS measure of happiness is one of the most widely used instruments to assess subjective happiness in different languages around the world (Extremera and FernándezBerrocal, 2014). Nevertheless, brief self-report measures of happiness have their limitations. Future studies should also explore and replicate these findings using other approaches to measure well-being and, for example, comparing hedonic and eudaimonic views of happiness.

Our data indicate a quite small (1\%) effect size for the three-way interaction among extraversion, quality of social relationships and emotion regulation ability. This result should therefore be considered preliminary and verified in future studies, preferably in different ethnicities. Nevertheless, we believe that this $1 \%$ interaction has real-world significance because it emerged from sixth-order regression, and because interactions of 1-5\% between well-established constructs are considered meaningful by many researchers (Shulman and Hemenover, 2006).

It would be interesting in future research to examine how emotion regulation ability interacts with social relationships and personality dimensions (e.g., extraversion and neuroticism) to influence variables related to mental health, such as anxiety, depression, perceived stress or consumption of addictive substances. For instance, it may be fruitful to examine whether interactions of some of these variables are associated with reduced symptomatology for these pathologies.

Future studies should also explore the effect of cultural dimensions such as individualism/collectivism (Ogihara and Uchida, 2014) on how much the quality of social relationships and emotion regulation ability influence the relationship between extraversion and happiness. Other mechanisms related to emotion regulation ability, such as self-control (Cheung et al., 2014), emotional regulation strategies (Cabello et al., 2013) and implicit theories (Cabello et al., 2015), may also be important for understanding the relationship between extraversion and happiness.

Finally, longitudinal interventional studies should be undertaken to test whether emotional regulation training can help both introverts and extraverts construct better social relations and become happier. Such research may provide more insight into experience- and age-dependent evolution in the association between extraversion and happiness, as well as in the influence of factors like quality of social relationships and emotion regulation ability on that association (Cabello et al., 2014). Evidence suggests that training in social and emotional competencies is crucial and should begin in the first years of life (Durlak et al., 2011).

\section{Conclusions}


This exploratory investigation is the first to test different models that consider quality of social relationships and emotion regulation ability evaluated by MSCEIT as mediator and/or moderator variables that enhance the effects of extraversion on happiness in a large adult community sample. Previous authors have noted that the direct, indirect, and interaction effects of several variables affecting happiness are not mutually exclusive. In other words, the association between extraversion and happiness is likely to be multiply determined (Lischetzke and Eid, 2006; Lucas and Baird, 2004). Our research investigated these mediation and interaction processes and revealed that the quality of social relationships and emotion regulation ability are relevant to our understanding of complex associations between extraversion and happiness.

Our study, together with the literature from which it emerged, suggests that many things can strongly influence one's happiness, including personality traits such as extraversion and neuroticism. Nevertheless, even introverts can achieve happiness if they succeed in developing a high quality of social relationships and in managing their emotions intelligently (Diener and Seligman, 2002; Sheldon and Lyubomirsky, 2007; Mayer et al., 2008b).

\section{References}

Argyle, M., and Lu, L. (1990). Happiness and social skills. Pers. Individ. Dif. 11, 1255-1261.

Argyle, M., Martin, M., and Lu, L. (1995). "Testing for stress and happiness: The role of social and cognitive factors," in Stress and emotion, eds. C. D. Spielberger and I. G. Sarason (Washington, DC: Taylor \& Francis), 173-187.

Aristotle (1984). "Ethics," in The Complete Works of Aristotle: The Revised Oxford Translation, Volume 2., ed. Jonathan Barnes (Princeton, NJ: Princeton University Press).

Bastian, V. A., Burns, N. R., and Nettelbeck, T. (2005). Emotional intelligence predicts life skills , but not as well as personality and cognitive abilities. Pers. Individ. Dif. 39, 1135-1145. doi:10.1016/j.paid.2005.04.006.

Benet-Martínez, V., and John, O. P. (1998). Los Cinco Grandes across cultures and ethnic groups: multitrait multimethod analyses of the Big Five in Spanish and English. J. Pers. Soc. Psychol. 75, 729-50.

Brackett, M. A., and Mayer, J. D. (2003). Convergent, discriminant, and incremental validity of competing measures of emotional intelligence. Personal. Soc. Psychol. Bull. 29, 1147-58. doi:10.1177/0146167203254596.

Brackett, M. A., Rivers, S. E., Shiffman, S., Lerner, N., and Salovey, P. (2006). Relating emotional abilities to social functioning: a comparison of self-report and performance measures of emotional intelligence. J. Pers. Soc. Psychol. 91, 780-95. doi:10.1037/00223514.91.4.780.

Cabello, R. and Fernández-Berrocal, P. (2015). Implicit theories and ability emotional intelligence. Front. Psychol. 6:700. doi: 10.3389/fpsyg.2015.00700. 
Cabello, R., Navarro Bravo, B., Latorre, J. M., and Fernández-Berrocal, P. (2014). Ability of university-level education to prevent age-related decline in emotional intelligence. Front. Aging Neurosci. 6, 7. doi:10.3389/fnagi.2014.00037.

Cabello, R., Salguero, J. M., Fernández-Berrocal, P., and Gross, J. J. (2013). A Spanish Adaptation of the Emotion Regulation Questionnaire. Eur. J. Psychol. Assess. 29, 234-240. doi: $10.1027 / 1015-5759 / \mathrm{a} 000150$.

Chamorro-Premuzic, T., Bennett, E., and Furnham, A. (2007). The happy personality: Mediational role of trait emotional intelligence. Pers. Individ. Dif. 42, 1633-1639. doi:10.1016/j.paid.2006.10.029.

Cheng, H., and Furnham, A. (2003). Personality, self-esteem, and demographic predictions of happiness and depression. Pers. Individ. Dif. 34, 921-942. doi:10.1016/S01918869(02)00078-8.

Cheng, H., and Furnham, A. (2014). The Associations Between Parental Socio-Economic Conditions, Childhood Intelligence, Adult Personality Traits, Social Status and Mental Well-Being. Soc. Indic. Res. 117, 653-664. doi:10.1007/s11205-013-0364-1.

Cheung, T. T. L., Gillebaart, M., Kroese, F., and De Ridder, D. (2014). Why are people with high self-control happier? The effect of trait self-control on happiness as mediated by regulatory focus. Front. Psychol. 5, 1-6. doi:10.3389/fpsyg.2014.00722.

Côté, S. (2014). Emotional Intelligence in Organizations. Annu. Rev. Organ. Psychol. Organ. Behav. 1, 459-488. doi:10.1146/annurev-orgpsych-031413-091233.

Cremers, H., van Tol, M.-J., Roelofs, K., Aleman, A., Zitman, F. G., van Buchem, M. a, Veltman, D. J., and van der Wee, N. J. a (2011). Extraversion is linked to volume of the orbitofrontal cortex and amygdala. PLoS One 6, e28421.

DeNeve, K. M., and Cooper, H. (1998). The happy personality: a meta-analysis of 137 personality traits and subjective well-being. Psychol. Bull. 124, 197-229.

Diener, E., and Seligman, M. E. P. (2002). Very Happy People. Psychol. Sci. 13, 81-84.

Durlak, J. A., Weissberg, R. P., Dymnicki, A. B., Taylor, R. D., and Schellinger, K. B. (2011). The impact of enhancing students' social and emotional learning: a meta-analysis of schoolbased universal interventions. Child Dev. 82, 405-32. doi:10.1111/j.14678624.2010.01564.x.

English, T., John, O. P., Srivastava, S., and Gross, J. J. (2012). Emotion Regulation and PeerRated Social Functioning: A Four-Year Longitudinal Study. J. Res. Pers. 46, 780-784. doi:10.1016/j.jrp.2012.09.006. 
Extremera, N., and Fernández-Berrocal, P. (2014). The Subjective Happiness Scale: Translation and Preliminary Psychometric Evaluation of a Spanish Version. Soc. Indic. Res. 119, 473481. doi:10.1007/s11205-013-0497-2.

Extremera, N., Fernández-Berrocal, P., and Salovey, P. (2006). Spanish version of the MayerSalovey-Caruso Emotional Intelligence Test (MSCEIT). Version 2.0: reliabilities, age and gender differences. Psicothema 18 Suppl, 42-8.

Extremera, N., Ruiz-Aranda, D., Pineda-Galán, C., and Salguero, J. M. (2011). Emotional intelligence and its relation with hedonic and eudaimonic well-being: A prospective study. Pers. Individ. Dif. 51, 11-16. doi:10.1016/j.paid.2011.02.029.

Furman, W. (1996). "The measurement of friendship perceptions: Conceptual and methodological issues," in The company they keep: friendships in childhood and adolescence, eds. W. M. Bukowski, A. F. Newcomb, and W. W. Hartup (New York, NY: Cambridge University Press), 41-65.

Furman, W., and Buhrmester, D. (1985). Children's perceptions of the personal relationships in their social networks. Dev. Psychol. 21, 1016-1024. doi:10.1037//0012-1649.21.6.1016.

Gallagher, E., and Vellabrodrick, D. (2008). Social support and emotional intelligence as predictors of subjective well-being 5 . Pers. Individ. Dif. 44, 1551-1561. doi:10.1016/j.paid.2008.01.011.

Hafen, C. a., Singh, K., and Laursen, B. (2011). The Happy Personality in India: The Role of Emotional Intelligence. J. Happiness Stud. 12, 807-817. doi:10.1007/s10902-010-9228-4.

Hayes, A. F. (2013). Introduction to Mediation, Moderation, and Conditional Process Analysis: A Regression-Based Approach. New York: Guilford Press.

Hayes, A. F., and Matthes, J. (2009). Computational procedures for probing interactions in OLS and logistic regression: SPSS and SAS implementations. Behav. Res. Methods 41, 924-36. doi:10.3758/BRM.41.3.924.

Hills, P., and Argyle, M. (2001). Happiness , introversion \pm extraversion and happy introverts. Pers. Individ. Dif. 30, 595-608.

Hotard, S. R., McFatter, R., McWhirter, R. M., and Stegall, M. (1989). Interactive Effects of Extraversion, Neuroticism, and Social Relationships on Subjective Well-Being. J. Pers. Soc. Psychol. 57, 321-331.

John, O. P., and Srivastava, S. (1999). "The Big Five trait taxonomy: History, measurement, and theoretical perspectives.," in Handbook of personality theory and research, eds. L. A. Pervin and O. P. John (New York: Guilford Press), 102-138. 
Joseph, D. L., and Newman, D. a (2010). Emotional intelligence: an integrative meta-analysis and cascading model. J. Appl. Psychol. 95, 54-78. doi:10.1037/a0017286.

Lee, R. M., Dean, B. L., and Jung, K.-R. (2008). Social connectedness, extraversion, and subjective well-being: Testing a mediation model. Pers. Individ. Dif. 45, 414-419. doi:10.1016/j.paid.2008.05.017.

Lischetzke, T., and Eid, M. (2006). Why extraverts are happier than introverts: the role of mood regulation. J. Pers. 74, 1127-61. doi:10.1111/j.1467-6494.2006.00405.x.

Lopes, P. N., Nezlek, J. B., Extremera, N., Hertel, J., Fernández-Berrocal, P., Schütz, A., and Salovey, P. (2011). Emotion regulation and the quality of social interaction: does the ability to evaluate emotional situations and identify effective responses matter? J. Pers. 79, 42967. doi:10.1111/j.1467-6494.2010.00689.x.

Lopes, P. N., Salovey, P., and Straus, R. (2003). Emotional intelligence, personality, and the perceived quality of social relationships. Pers. Individ. Dif. 35, 641-658.

Lucas, R. E. (2007). Personality and the Pursuit of Happiness. Soc. Personal. Psychol. Compass 1, 168-182. doi:10.1111/j.1751-9004.2007.00009.x.

Lucas, R. E., and Baird, B. M. (2004). Extraversion and emotional reactivity. J. Pers. Soc. Psychol. 86, 473-85. doi:10.1037/0022-3514.86.3.473.

Lucas, R. E., Dyrenforth, P. S., and Diener, E. (2008a). Four Myths about Subjective Well-being. Soc. Personal. Psychol. Compass 2, 2001-2015. doi:10.1111/j.1751-9004.2008.00140.x.

Lucas, R. E., and Fujita, F. (2000). Factors influencing the relation between extraversion and pleasant affect. J. Pers. Soc. Psychol. 79, 1039-1056. doi:10.1037//0022-3514.79.6.1039.

Lucas, R. E., Le, K., and Dyrenforth, P. S. (2008b). Explaining the extraversion/positive affect relation: sociability cannot account for extraverts' greater happiness. J. Pers. 76, 385-414. doi:10.1111/j.1467-6494.2008.00490.x.

Lyubomirsky, S., King, L., and Diener, E. (2005). The Benefits of Frequent Positive Affect: Does Happiness Lead to Success? Psychol. Bull. 131, 803-855. doi:10.1037/00332909.131.6.803.

Lyubomirsky, S., and Lepper, H. (1999). A measure of subjective happiness: Preliminary reliability and construct validation. Soc. Indic. Res. 46, 137-155.

Mayer, J. D., Roberts, R. D., and Barsade, S. G. (2008a). Human abilities: emotional intelligence. Annu. Rev. Psychol. 59, 507-36. doi:10.1146/annurev.psych.59.103006.093646. 
Mayer, J. D., and Salovey, P. (1997). "What is emotional intelligence?," in Emotional Development and Emotional Intelligence: implications for educators, eds. P. Salovey and D. Sluyter (New York: Basic Books), 3-31.

Mayer, J. D., Salovey, P., and Caruso, D. R. (2008b). Emotional intelligence: new ability or eclectic traits? Am. Psychol. 63, 503-17. doi:10.1037/0003-066X.63.6.503.

Mayer, J. D., Salovey, P., and Caruso, D. R. (2002). The Mayer-Salovey-Caruso Emotional Intelligence Test (MSCEIT), Version 2.0. Toronto, Ontario, Canada: Multi-Health Systems.

Mayer, J. D., Salovey, P., Caruso, D. R., and Sitarenios, G. (2003). Measuring emotional intelligence with the MSCEIT V2.0. Emotion 3, 97-105. doi:10.1037/1528-3542.3.1.97.

Oerlemans, W. G. M., and Bakker, A. B. (2014). Why extraverts are happier: A day reconstruction study. J. Res. Pers. 50, 11-22. doi:10.1016/j.jrp.2014.02.001.

Ogihara, Y., and Uchida, Y. (2014). Does individualism bring happiness? Negative effects of individualism on interpersonal relationships and happiness. Front. Psychol. 5, 135. doi:10.3389/fpsyg.2014.00135.

Preacher, K. J., Rucker, D. D., and Hayes, A. F. (2007). Addressing Moderated Mediation Hypotheses: Theory, Methods, and Prescriptions. Multivariate Behav. Res. 42, 185-227. doi: $10.1080 / 00273170701341316$.

Salami, S. . (2011). Personality and psychological well-being of adolescents: The moderating role of emotional intelligence. Soc. Behav. Pers. 39, 785-794. doi:10.2224/sbp.2011.39.6.785.

Schimmack, U., Oishi, S., Furr, R. M., and Funder, D. C. (2004). Personality and life satisfaction: a facet-level analysis. Personal. Soc. Psychol. Bull. 30, 1062-75. doi:10.1177/0146167204264292.

Sheldon, K. M., and Lyubomirsky, S. (2007). Is It Possible to Become Happier? (And If So, How?). Soc. Personal. Psychol. Compass 1, 129-145. doi:10.1111/j.17519004.2007.00002.x.

Shulman, T. E., and Hemenover, S. H. (2006). Is dispositional emotional intelligence synonymous with personality? Self Identity 5, 147-171. doi:10.1080/15298860600586206.

Smillie, L. D., Cooper, A. J., Wilt, J., and Revelle, W. (2012). Do extraverts get more bang for the buck? Refining the affective-reactivity hypothesis of extraversion. J. Pers. Soc. Psychol. 103, 306-26. doi:10.1037/a0028372.

Steel, P., Schmidt, J., and Shultz, J. (2008). Refining the relationship between personality and subjective well-being. Psychol. Bull. 134, 138-161. doi:10.1037/0033-2909.134.1.138. 
617 Webb, C. A., Schwab, Z. J., Weber, M., DelDonno, S., Kipman, M., Weiner, M. R., and 618 Killgore, W. D. S. (2013). Convergent and divergent validity of integrative versus mixed 619 model measures of emotional intelligence. Intelligence 41, 149-156.

620 doi:10.1016/j.intell.2013.01.004.

621 Zeidner, M., and Olnick-Shemesh, D. (2010). Emotional intelligence and subjective well-being 622 revisited. Pers. Individ. Dif. 48, 431-435. doi:10.1016/j.paid.2009.11.011.

623 


\section{Table $\mathbf{1}$ (on next page)}

Descriptive statistics for total sample and men and women, range, Cronbach's $\alpha$ and correlation with age of key variables

${ }^{* *} p<.01 . N=1006$. 
1 Table 1. Descriptive statistics for the total sample and separately for men and women, 2 Cronbach's $\alpha$ and correlation of key variables with age

\begin{tabular}{|c|c|c|c|c|c|c|c|c|c|}
\hline \multirow[b]{2}{*}{ Variable } & \multicolumn{3}{|l|}{ Total } & \multicolumn{2}{|l|}{ Men } & \multicolumn{4}{|c|}{ Women } \\
\hline & $M$ & $S D$ & Range & $M$ & $S D$ & $M$ & $S D$ & $\alpha$ & $\begin{array}{l}\text { Correlation } \\
\text { with Age }\end{array}$ \\
\hline Age & 39.53 & 14.96 & $18-80$ & 42.9 & 14.73 & 37.07 & 14.64 & & \\
\hline Happiness & 5.09 & 1.05 & $1-7$ & 5.15 & 1.03 & 5.04 & 1.07 & .80 & .00 \\
\hline Extraversion & 3.45 & .69 & $1.5-5$ & 3.40 & .70 & 3.48 & .68 & .78 & -.02 \\
\hline Neuroticism & 2.96 & .73 & $1.1-5$ & 2.77 & .73 & 3.10 & .70 & .76 & $-.08^{* *}$ \\
\hline Quality of social relationships & 19.66 & 4.43 & $3-27$ & 18.90 & 4.63 & 20.20 & 4.20 & .94 & $-.39^{* *}$ \\
\hline Emotion regulation ability & 98.48 & 14.15 & $65.10-134.90$ & 96.58 & 15.08 & 99.86 & 13.29 & .80 & $-.16^{* *}$ \\
\hline
\end{tabular}

$\begin{array}{cc}3 & { }^{* *} p<.01 \\ 4 & N=1006 \\ 5 & \end{array}$




\section{Table 2 (on next page)}

Correlations of key variables.

${ }^{* *} p<.01 . N=1006$. 
1 Table 2. Correlations of key variables.

\begin{tabular}{|c|c|c|c|c|}
\hline \multirow{2}{*}{ Variable } & \multicolumn{4}{|c|}{ Correlations } \\
\hline & 1 & 2 & 3 & 4 \\
\hline \multicolumn{5}{|l|}{ 1. Happiness } \\
\hline 2. Extraversion & $.35^{* *}$ & & & \\
\hline 3. Neuroticism & $-.42^{* *}$ & $-.19^{* *}$ & & \\
\hline 4. Quality of social relationships & $.26^{* *}$ & $.20^{* *}$ & -.06 & \\
\hline 5. Emotion regulation ability & $.18^{* *}$ & $.08^{* *}$ & -.03 & $.20^{* *}$ \\
\hline $\begin{array}{c}*^{* *} p<.01 \\
N=1006\end{array}$ & & & & \\
\hline
\end{tabular}


Table 3 (on next page)

Serial mediation analysis to identify direct and indirect effects between extraversion and happiness.

Note. Coefficient $=$ nonstandardized $\mathrm{B}$ coefficients; $S E=$ standard errors; $\mathrm{Cl}=$ bias-corrected and accelerated 95\% confidence interval; $L L=$ lower limit, $U L=$ upper limit; $E=$ extraversion; $\mathrm{H}=$ happiness; $\mathrm{QSR}=$ quality of social relationship; $\mathrm{ERA}=$ emotion regulation ability; 10000 bootstrap samples. a Age, sex, and neuroticism were covaried. ${ }^{* * *} p<.001 . N=$ 1006. 
1 Table 3. Serial mediation analysis to identify direct and indirect effects between 2 extraversion and happiness.

\begin{tabular}{|c|c|c|c|c|c|}
\hline \multirow{2}{*}{ Effect } & \multirow{2}{*}{ Path } & \multirow{2}{*}{ Coefficient } & \multirow{2}{*}{$S E$} & \multicolumn{2}{|c|}{$95 \% \mathrm{CI}$} \\
\hline & & & & $L L$ & $U L$ \\
\hline Direct effect of E on QSR & $a_{1}$ & $1.0828^{* * *}$ & .1848 & .7202 & 1.4454 \\
\hline Direct effect of E on ERA & $a_{2}$ & .0036 & .0032 & -.0028 & 0099 \\
\hline Direct effect of QSR on ERA & $a_{3}$ & $.0022^{* * *}$ & .0005 & .0011 & .0033 \\
\hline Direct effect of QSR on $\mathrm{H}$ & $b_{1}$ & $.0467^{* * *}$ & .0071 & 0327 & .0606 \\
\hline Direct effect of ERA on $\mathrm{H}$ & $b_{2}$ & $1.9333^{* * *}$ & .4107 & 1.1273 & 2.7393 \\
\hline $\begin{array}{l}\text { Total effect of } E \text { on } H \text {, without } \\
\text { accounting for QSR and ERA }\end{array}$ & $c$ & $.4185^{* * *}$ & .0426 & 3348 & .5021 \\
\hline $\begin{array}{l}\text { Direct effect of } E \text { on } H \text { when } \\
\text { accounting for QSR and ERA }\end{array}$ & $c^{\prime}$ & $.3564^{* * *}$ & .0419 & 2743 & 4386 \\
\hline Total indirect effect & $a b$ & .0620 & .0149 & .0353 & .0946 \\
\hline Indirect via QSR & $a_{1} b_{1}$ & .0505 & .0136 & .0272 & .0810 \\
\hline Indirect via QSR and ERA & $a_{1} a_{3} b_{2}$ & .0046 & .0018 & .0019 & .0096 \\
\hline Indirect via ERA & $a_{2} b_{2}$ & .0069 & .0069 & -.0054 & .0224 \\
\hline
\end{tabular}

3 Note. Coefficient $=$ nonstandardized B coefficients; $S E=$ standard errors; $\mathrm{CI}=$ bias-corrected and 4 accelerated 95\% confidence interval; $L L=$ lower limit, $U L=$ upper limit; $\mathrm{E}=$ extraversion; $\mathrm{H}=$ 5 happiness; QSR = quality of social relationship; ERA = emotion regulation ability; 10000 6 bootstrap samples.

$7 \quad{ }^{a}$ Age, sex, and neuroticism were covaried.

$8{ }^{* * *} p<.001$.

$9 \quad N=1006$. 
1

Illustration of the indirect effects model for serial mediation.

In this model, quality of social relationships and emotion regulation ability mediate the relationship between extraversion and happiness.

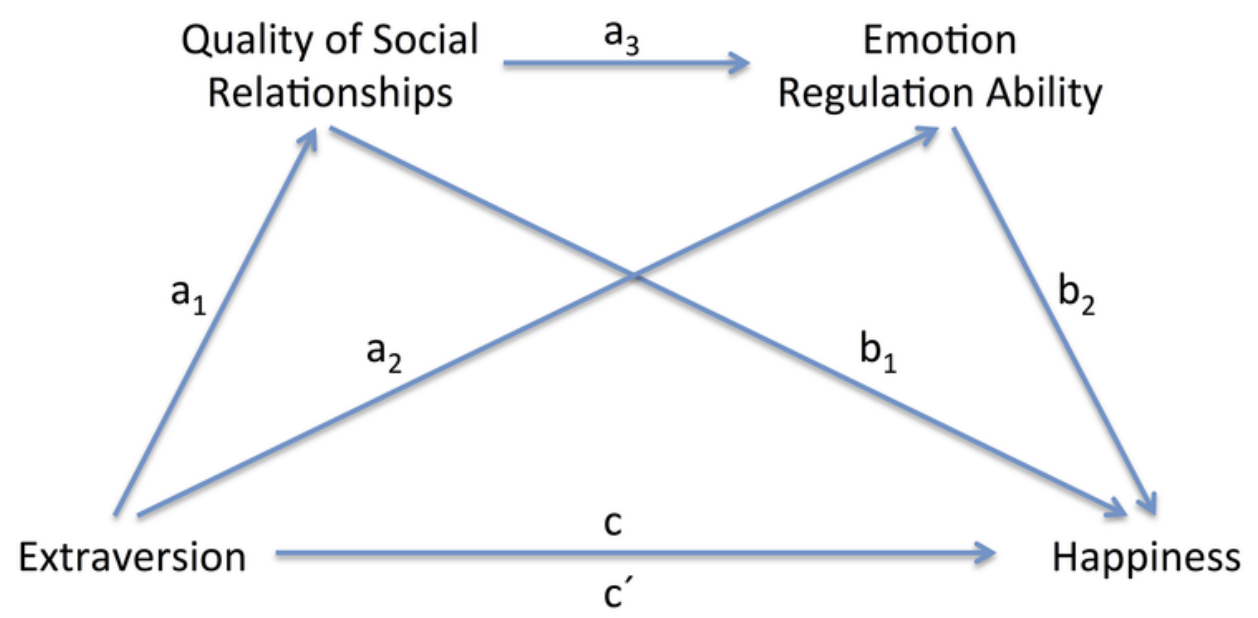


2

Illustration of the three-way interaction model.

In this model, quality of social relationships and emotion regulation ability moderate the relationship between extraversion and happiness.

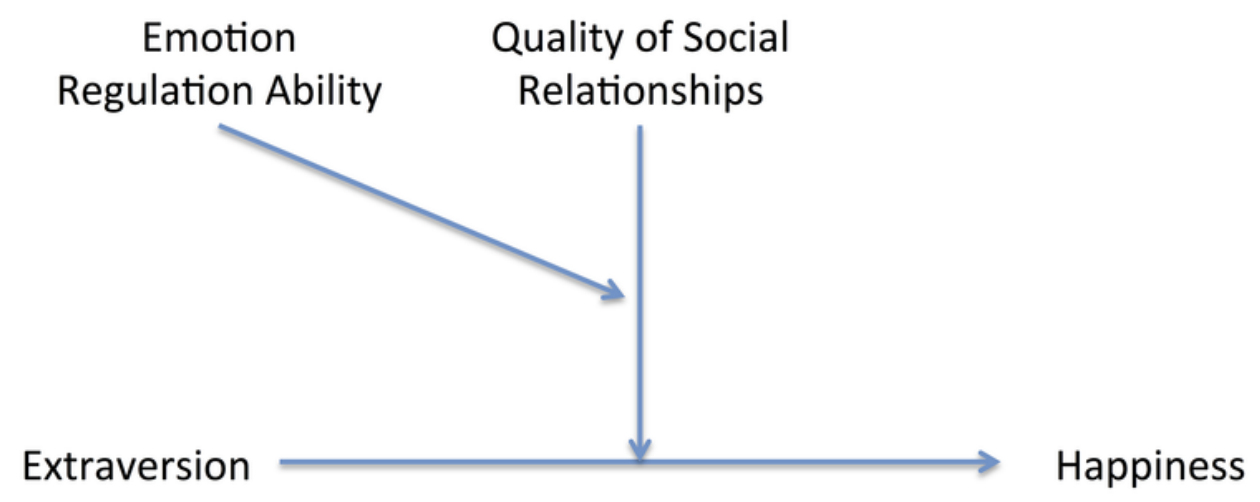


3

Three-way interaction model to examine how the introversion/extraversion dimension affects happiness.

In this model, the quality of social relationships and emotion regulation ability moderate the relationship between extraversion and happiness. Results are shown separately for introverted (A) and extraverted (B) participants. ${ }^{* * *} \mathrm{p}<.001 . N=1006$.

\section{A. Introverted}

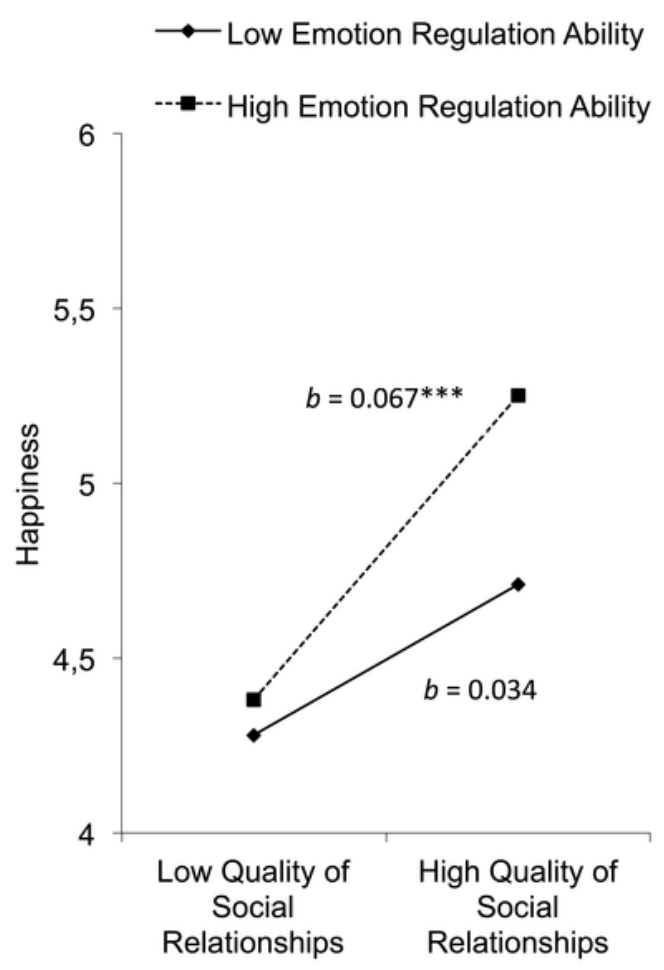

B. Extraverted

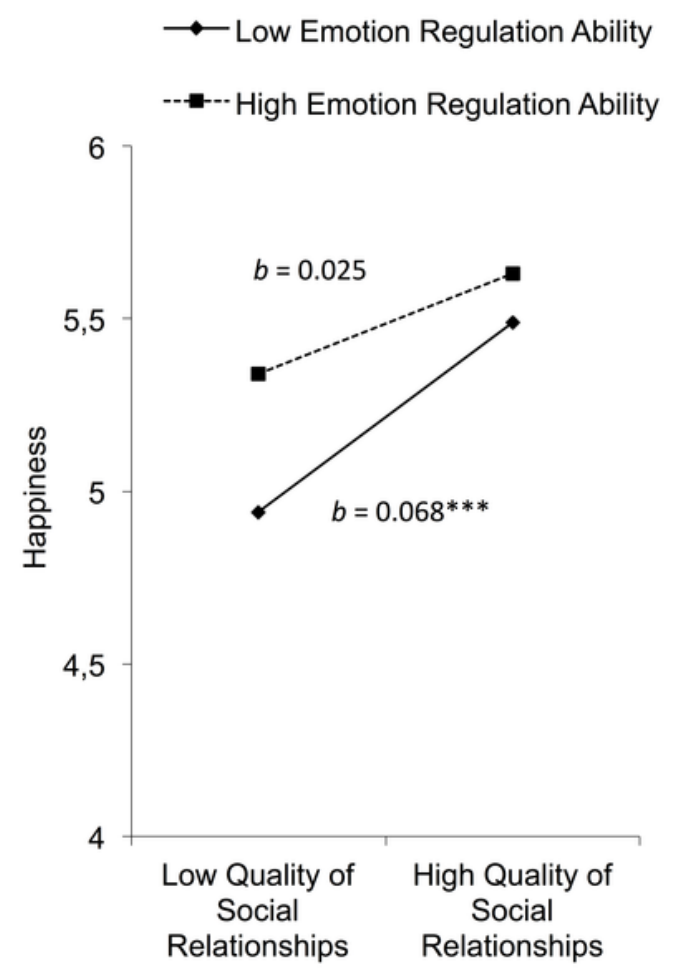

